\title{
ЦИФРОВОЙ МАРКЕТИНГ КАК ТЕХНОЛОГИЯ ПРОДВИЖЕНИЯ ОРГАНИЧЕСКОЙ ПРОДУКЦИИ
}

\author{
Дадаев Я.Э. \\ ФГБОУ ВО «Чеченский государственный университет», \\ г. Грозный, Россия
}

Целью статьи является исследование сущуности и содержательного состава инструментов иифрового маркетинга, проведение сравнительного анализа традиционных и иифровых медиа, определение преимуществ и перспектив использования инструментов ицироввого маркетинга в процессе продвижения органической продукиии на рынок.

Ключевые слова: маркетинг, цифровая экономика, сельское хозяйство, органическая продукция, бизнес.

Во всем мире активно сокращается доля традиционной экономики, а цифровой - увеличивается, предоставляя существенные преимущества странам и бизнесу. Именно цифровая экономика является акселератором социально-экономической жизни общества в современном мире, именно она способна стремительно повысить ВВП страны.

На сегодня доля цифровой экономики в ВВП крупнейших стран мира составляет от 6 до 15\%. В 2030 году она вырастет до 50-60\%. В России сейчас ее доля составляет около $5.1 \%$ [1].

Успешный опыт Ирландии, Швеции и Израиля свидетельствует, что непосредственный эффект от комплексного развития цифровой экономики составляет $20 \%$ ВВП в течение пяти лет, a ROI инвестиции в цифровую трансформацию достигает 500\%. Цифровая экономика является главным приоритетом для Германии и Великобритании [1].

«Понятие «органическое сельское хозяйство» является ключевым для понимания сущности и преимущества органики перед продукцией конвенционного производства. Органическое сельское хозяйство имеет глубокие корни, в первую очередь, в аграрной науке и практике. Но в качестве самостоятельного направления органическое сельскохозяйственное производство стало формироваться лишь в начале XX века, прежде всего в Европе, а также в США» [2].

Наша страна на протяжении последних 20 лет все активнее приобщается к международному органическому движению, поскольку все больше производит, экспортирует и потребляет органическую продукцию. В последнее время органическое направление производства занимает стратегическую позицию не только в развитии аграрной сферы, но и всей нашей национальной экономики. Но, заметим, что развитие органической сферы происходит в условиях высокой неопределенности как для производителей, так и для 
потребителей органики, поскольку требует совершенствования системы научно-теоретического и нормативно-правового обоснования. В первую очередь, речь идет об основных определениях и понятиях в сфере производства, обращения, маркировки, потребления и законодательного обеспечения органической сферы.

Цифровой или digital-маркетинг, представляет собой инструменты коммуникаций с потребителем, которые реализуются с помощью цифровых каналов. Кроме того, цифровой маркетинг имеет свое воплощение не только в онлайн каналах, но и в офлайн каналах в виде ссылок на электронные ресурсы и QR-кодов. При продвижении органической продукции целесообразно использовать возможность не только ознакомления с существующей продукцией, но и осуществления онлайн-заказа.

Digital-маркетинг имеет ряд отличий по сравнению с интернетмаркетингом. Маркетологи взаимодействуют с клиентами через соответствующие каналы. Сегодня существует множество каналов digitalмаркетинга для коммуникации с клиентами: от взаимодействия на сайте к личному общению; от рекламы в печатных изданиях до рекламы на телевидении; от электронных писем, рассылки новостей, блогов, социальных медиа писем и брошюр, которые отправляются почтой. Количество каналов, которые можно использовать, только растет. На рис. 1 показаны различные каналы digital-маркетинга.

От качества и уникальности контента веб-ресурса зависит приток посетителей - потенциальных потребителей органической продукции. Сайт может быть привлекательным с точки зрения технического дизайна и его исполнение может быть на высоком уровне, но не уникальный низкокачественный контент снизит желание пользоваться ресурсом. Создавая сайт, производителям органической продукции необходимо постоянно наполнять его различными материалами для соответствующего роста популярности и увеличения запросов в поисковых сетях.

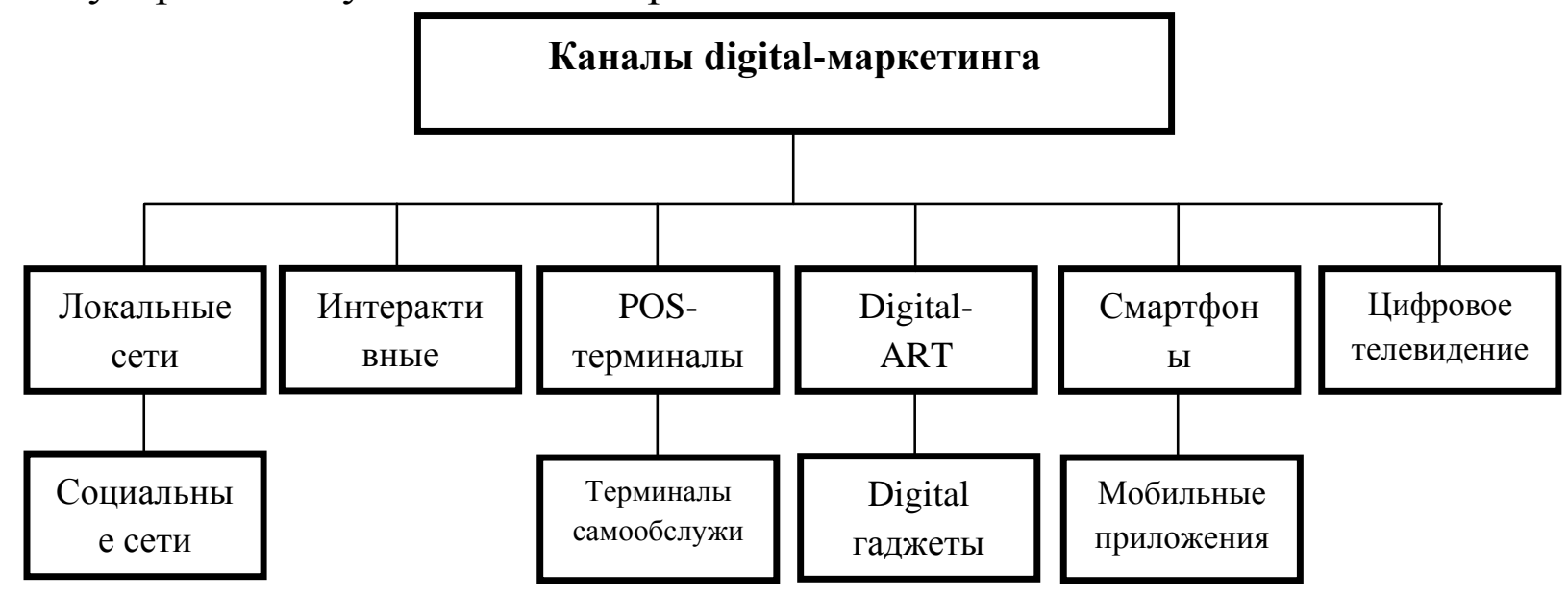

Рис. 1 - Современные каналы digital-маркетинга Источник: разработано автором 
Цифровые технологии прочно вошли в жизнь не только простых пользователей. Безусловно, производители органической продукции стремятся использовать самые современные каналы коммуникации для того, чтобы, с одной стороны, чтобы клиентам было легче найти действительно органический продукт, а с другой - производителям проще расширять целевую аудиторию. Интерес к использованию digital-маркетинга при продвижении органической продукции с каждым годом только растет. Менеджеры фирм теперь должны не только обеспечивать продажу органической продукции, но и пытаться привлечь потребителей к новым каналам и цифровым технологиям.

Для этого в работе маркетингового подразделения производителей органической продукции предполагается использование большого количества digital-каналов и инструментов. Одним из таких инструментов является e-mailрассылка. Email коммуникации по-прежнему играют значительную роль. Именно такой канал общения остается одним из самых эффективных. По мнению некоторых специалистов, этот канал устарел и перестает работать, но статистика показывает, что рассылка, может достигать показателя ответов до $5 \%$ и приносить более 50\% дохода от всего объема digital-продаж. При этом нужно помнить, что $2 / 3$ потребителей готовы получать обновления каждый месяц. Также следует правильно подходить к формату, ведь 50\% всех emailсообщений открывается на смартфонах. Многие производители пытаются усовершенствовать и обновить данный канал. С помощью электронной почты они хотят наладить с потенциальными потребителями персональное общение, установить более тесные взаимоотношения и повысить лояльность своих потребителей.

Один из каналов digital-маркетинга, который приобрел значительное развитие-это маркетинг в социальных медиа. Однако сайт производителей органической продукции и механизм заказа-онлайн остаются лучшей возможностью продажи. В среднем потребители проводят 6 минут на вебсайтах производителей. 6 минут - это большая возможность привлечь будущих потребителей красочными картинками, полным описанием продукции и привлекательными предложениями, которые помогут сделать решение о заказе. Еще один важный пункт - показать, что они получат в реальности, когда осуществят заказ. Здесь помогут фотографии, видео, а также 3D картинки и видео-экскурсии, например, по производству, которые становятся очень популярными.

К сожалению, отечественные производители органической продукции чаще всего предлагают уникальную экологически чистую продукцию и быструю доставку, не отражая свои предпочтения на сайте, упуская из вида необходимость размещения привлекательных текстов, изображений и ярких приемов привлечения аудитории. Множество «hitech» новинок по непонятной причине проходит мимо производителей органической продукции, многие из которых ограничиваются несколькими фотографиями, кратким описанием продукта и перечислением ассортимента. Хотя эти инструменты не относятся к 
обязательным, но включив их в маркетинговый комплекс, производители органической продукции гарантированно преуспеют в продажах.

На сайте каждого производителя органической продукции должна быть размещена не только базовая информация о продукте, но и, например, кулинарные рецепты для продуктов питания, тематические разделы, отвечающих запросам целевой аудитории (ассортимент, цена, особые предложения, акции и т.п.).

При этом следует оптимизировать сайт для поисковых систем. Это можно сделать с помощью процесса так называемой поисковой оптимизации, или SEO (англ. Search engine optimization). SEO имеет решающее значение, когда предприятие конкурирует с двумя другими аналогичными производителями органической продукции за верхнюю позицию для «производителя в [городе]», импровизация его позиции в поиске может привести к большому увеличению количества кликов на сайте производителя органической продукции. Вполне очевидно, что если посетителям нравится то, что они видят на сайте, есть большая вероятность осуществления заказа и увеличения частоты покупки органической продукции у данного производителя, а не у его конкурентов.

Еще одним трендом в сфере продвижения органической продукции через Digital-маркетинг является разработка собственных программ для смартфонов. Свои мобильные приложения, разработанные соответствующими специалистами, сегодня есть как у крупных товаропроизводителей, так и в небольших самостоятельных производителей.

При разработке мобильных приложений для производителей органической продукции обязательно нужно учитывать, какую функцию они должны выполнять. Среди основных функций программы производителей органической продукции можно выделить онлайн-заказ, «виртуальный ключ», ведение бонусной системы, информирование клиентов о специальных предложениях, общение с гостем через чат, мобильный сервис. Именно возможность предоставлять клиентам полезные советы во время онлайн-заказа и общаться с ними с помощью мобильного сервиса, делает мобильные технологии одними из наиболее эффективных способов взаимодействия производителей органической продукции с их потенциальными клиентами и соответствуют современным тенденциям развития бизнеса.

Используя инструменты digital-маркетинга, менеджеры производств органической продукции могут повысить маркетинговое влияния, увеличив количество реализованной продукции через онлайн-заказы. При этом, digitalмаркетинг не обязательно требует изучения множества новых инструментов и найма большого количества новых сотрудников.

Следует еще раз подчеркнуть, что digital-маркетинг более выгоден, чем традиционная рекламная кампания, особенно для малых производителей. Так, производители органической продукции, которые раньше не могли себе позволить бороться за внимание клиента с крупными игроками, теперь, с помощью digital-маркетинга, даже при небольших маркетинговых затратах, могут сформировать качественную кампанию для своей аудитории. 
Таким образом, digital-маркетинг открывает массу новых возможностей для органического бизнеса, улучшая при этом качество заказа и доставки и делая его более персонализированным для потенциальных потребителей.

\section{Список литературы}

1. Ассоциация электронных коммуникаций (РАЭК) [Электронный pecypc] - Режим доступа: https://raec.ru/about [дата обращения 12.03.2020].

2. Бекмурзаев И.Д., Курбанов А.Х. Развитие цифровой экономики как элемент стратегии общественного развития в России // Финансовая экономика. № 5, 2019. - с. 556-558.

3. Дадаев Я.Э., Современные подходы к определению понятия органического сельского хозяйства // Вестник Чеченского государственного университета. Научно-аналитический журнал. - Грозный, № 1 (38), 2020. - с. 23-30.

4. Дадаев Я.Э., Маркетинговое управление аграрным производством: сущность и особенности // Вестник Чеченского государственного университета. Научно-аналитический журнал. - Грозный, № 1 (33), 2019. - с. 73-80. 